\title{
Prevalence of varicella-zoster virus genotypes in Australia characterized by high-resolution melt analysis and ORF22 gene analyses
}

\author{
Cheryl S. Toi and Dominic E. Dwyer \\ Clinical Virology, Centre for Infectious Diseases and Microbiology - Public Health, Institute of \\ Clinical Pathology and Medical Research, Westmead Hospital, NSW 2145, Australia
}

Correspondence

Cheryl S. Toi

cheryl.toi@swahs.health.nsw.gov.

au

Received 9 February 2010

Accepted 7 May 2010

\begin{abstract}
DNA sequence variation analysis has divided varicella-zoster virus (VZV; Human herpesvirus 3) into distinct geographical clades: European, Asian, African and Japanese. These genotypes are becoming increasingly prevalent within regions atypical to their original source and there has been the suggestion of recombination between genotypes. Seventy-eight clinical isolates from hospitalized patients with varicella were collected in New South Wales, the Northern Territory, Western Australia and Victoria from 2006 to 2009. The wild-type strains and the vaccine strain (vOka) were differentiated by single nucleotide polymorphism detection using high-resolution melt analysis of five target genes (ORF1, $-21,-37,-60$ and -62), and by DNA sequence analysis of a $484 \mathrm{bp}$ region of ORF22. Phylogenetic analysis showed that $46 \%(36 / 78)$ of the clinical isolates were European clade 1 (C/E1) strains, $21 \%$ (16/78) were European clade 3 (B/E2) strains, $12 \%$ (9/78) were Asian/African clade 5 (A/M1) strains, $10 \%$ (8/78) were clade 4 (J2/M2), $6 \%$ (5/78) were clade $2(\mathrm{~J} / \mathrm{J})$ and $5 \%(4 / 78)$ belonged to the novel clade VI. No significant association was shown between VZV genotype and region, age or gender. Although European strains were most common, the results suggest an increase in African/Asian, Japanese and clade VI genotypes circulating in Australia.
\end{abstract}

\section{INTRODUCTION}

Chickenpox (varicella) is a childhood disease caused by the dsDNA varicella-zoster virus (VZV; Human herpesvirus 3). After primary infection, the virus becomes latent in sensory ganglia and has the potential to reactivate to produce herpes zoster (shingles), especially in older adults and immunocompromised people (Hope-Simpson, 1965). Global vaccination has reduced the disease burden (Vazquez et al., 2001). In Australia, a varicella vaccine was licensed for use in 1999, but the vaccination programme was only publicly funded in 2005 , so the impact of varicella vaccination on disease incidence has not yet been fully established because of limited data. However, surveillance studies have indicated that mass vaccination is associated with an increasing mean age of infection and absolute increases in varicella incidence among older groups (Cohen \& Lipsitch, 2008), especially among unvaccinated adults (Brisson et al., 2000; Edmunds \& Brisson, 2002). This could be attributed to a decrease in exogenous boosting through lowered exposure to children with varicella and a waning cell-mediated immunity to VZV. Reports show that recurrent herpes zoster can be caused by genetically distinct genotypes (Taha et al., 2006).

Abbreviations: HRMA, high-resolution melt analysis; SNP, single nucleotide polymorphism.
This potentially presents a higher burden of disease. It is uncertain whether specific VZV genotypes are more virulent and possess an increased potential to cause severe complications. A single amino acid change in VZV isolated from patients with primary varicella has been shown to enhance the ability of the virus to spread both in vitro and in human skin implants in SCID-hu mice (Grose et al., 2004).

Genotypic data show that VZV is specific to geographical location (Barrett-Muir et al., 2002, 2003; Quinlivan et al., 2002) and can be classified into European, African, Asian and Japanese genotypes. More recently, an increasing number of mixed strains have been identified, suggesting genetic recombination (Loparev et al., 2004; Norberg et al., 2006; Peters et al., 2006). The nomenclature of VZV genotypes has been based on different molecular typing methods, and only recently has a new universal nomenclature been introduced, separating the genotypes into five major clades (1-5) with two novel clades, VI and VII, still to be confirmed (Breuer et al., 2010; Sengupta et al., 2009).

Data on Australian VZV genotypes in Australia are limited (LaRussa et al., 1998; Loparev et al., 2007). Moreover, the information is limited on which circulating genotypes are associated with severe complications. Using two popular genotyping strategies, the scattered single-nucleotide polymorphism (SNP) method (Parker et al., 2006) and 
sequence analysis of ORF22 (Loparev et al., 2004, 2007) targeting four nucleic acid mutations, this investigation reports on VZV genotypes circulating within Australia from 2006 to 2009 and the possible impact of the newly introduced varicella vaccine on VZV lineages. For simplicity, this study classified VZV genotypes using the agreed universal nomenclature, with reference to the classification by Barrett-Muir et al. (2003) and Loparev et al. (2004).

\section{METHODS}

VZV clinical samples. A total of 78 clinical isolates were collected from 2006 to 2009 from individuals presenting with varicella complications requiring hospitalization. Varicella infection was diagnosed clinically by the onset of a vesicular skin rash. Patients were from the Royal Darwin Hospital in the Northern Territory $(n=31)$, the Princess Margaret Hospital $(n=28)$ in Western Australia, the Royal Children's Hospital, Victoria $(n=2)$, and Westmead Hospital $(n=15)$, Concord Hospital $(n=1)$ and Nepean Hospital $(n=1)$ in New South Wales. Forty-eight patients were male and 30 were female with ages ranging from 4 months to 83 years.

DNA was extracted from vesicular swabs, blood or cerebrospinal fluid using a PureLink Genomic DNA Mini kit (Invitrogen). The DNA concentration was measured at $A_{260} / A_{280}$ using UV spectrophotometry (Beckman DU Series 500) and the samples were diluted to a final concentration of $8 \mathrm{ng} \mu \mathrm{l}^{-1}$.

Laboratory controls comprising two preparations of the Oka/Merck (Varivax, CSL Biotherapies; Varilrix, GlaxoSmithKline) strains of the live, attenuated VZV (vOka) were propagated in MRC-5 cells and harvested at 8 days post-infection. A low-passage VZV clinical isolate, designated strain Schenke (VZV-S; Centre for Virus Research, Westmead Millennium Institute, NSW, Australia), was included as a wild-type laboratory reference.

Multi-SNP analysis. VZV strains were genotyped by real-time PCR amplification, followed by high-resolution melt analysis (HRMA) of SNPs using a method described previously (Toi \& Dwyer, 2008). Five ORFs were selected: 1 (SNP 685), 21 (SNP 33725), 37 (SNP 66288), 60 (SNP 101464) and 62 (SNP 106262). The gene targets, ranging between 65 and $103 \mathrm{bp}$ in size, were amplified in separate reactions using published primers (Parker et al., 2006).

Briefly, a Rotor-Gene 6000 (Qiagen) was used for real-time PCR amplification and HRMA of the five ORFs. The PCR was performed in a total volume of $20 \mu \mathrm{l}$ containing $40 \mathrm{ng}$ DNA, $200 \mathrm{nM}$ dNTPs, $300 \mathrm{nM}$ each primer, $2 \mu \mathrm{l} 10 \times$ PCR buffer (Sigma), $2.5 \mathrm{mM} \mathrm{MgCl}_{2}$, $1 \mu \mathrm{l} 20 \times$ EvaGreen (Biotium), 1 U JumpStart Taq DNA polymerase (Sigma) and RNase-/DNase-free water. The thermal cycling reactions consisted of initial denaturation for $1 \mathrm{~min}$ at $94{ }^{\circ} \mathrm{C}$, followed by 40 cycles of denaturation at $94{ }^{\circ} \mathrm{C}$ for $10 \mathrm{~s}$, annealing at $61{ }^{\circ} \mathrm{C}$ for $20 \mathrm{~s}$ and extension at $72{ }^{\circ} \mathrm{C}$ for $20 \mathrm{~s}$.

Amplification was followed immediately by HRMA, commencing with a pre-hold cycle $\left(30 \mathrm{~s}\right.$ at $\left.50{ }^{\circ} \mathrm{C}\right)$. Ramping conditions for the five gene targets were as follows: ORF $62\left(83-93{ }^{\circ} \mathrm{C}\right)$, ORF $60\left(80-90{ }^{\circ} \mathrm{C}\right)$ and ORF $37\left(72-82^{\circ} \mathrm{C}\right)$, and ORF 21 and 1 (73-83 $\left.{ }^{\circ} \mathrm{C}\right)$ with fluorescence data acquisition set at $0.1{ }^{\circ} \mathrm{C}$ increments. All amplicons were electrophoresed on a $2.5 \%$ agarose gel as a check for nonspecific products. Inclusion of the wild-type strain VZV-S and vaccine strains Varivax and Varilrix provided a reference point in meltingcurve shifts for distinguishing between wild-type strains, and between wild-type and vaccine strains. VZV-S is genetically similar to reference strain Dumas in ORF1, -21, -37, -60 and -62 .
DNA sequence analysis of ORF22. The method of Loparev et al. (2004) was used to genotype ORF22, with some modifications. Forward primer 5'-AACAAACGACTCGGGTTTTG-3' and reverse primer 5'-AGCCAATGCGGGTATTTGTA-3' spanning the region nt 37825-38309 of the gene target were designed with Primer-BLAST (http://blast.ncbi.nlm.nih.gov/Blast.cgi). This 484 bp fragment contains five SNPs capable of resolving five of the recognized VZV genotypes. The PCR was performed on a Veriti thermal cycler (Applied Biosystems) in a total volume of $25 \mu \mathrm{l}$ containing 100 300 ng DNA, $200 \mathrm{nM}$ dNTPs, $200 \mathrm{nM}$ each primer, $2 \mu \mathrm{l} 10 \times$ PCR buffer (Sigma), $2.5 \mathrm{mM} \mathrm{MgCl}_{2}, 1 \mathrm{U}$ JumpStart Taq DNA polymerase (Sigma) and RNase-/DNase-free water. The thermal cycling reactions consisted of initial denaturation for $1 \mathrm{~min}$ at $94{ }^{\circ} \mathrm{C}$, followed by 10 cycles of $94{ }^{\circ} \mathrm{C}$ for $20 \mathrm{~s}, 57{ }^{\circ} \mathrm{C}$ for $20 \mathrm{~s}$ and $72{ }^{\circ} \mathrm{C}$ for $30 \mathrm{~s}$, and 30 cycles of $94{ }^{\circ} \mathrm{C}$ for $20 \mathrm{~s}, 57{ }^{\circ} \mathrm{C}$ for $20 \mathrm{~s}$ and $72{ }^{\circ} \mathrm{C}$ for $30 \mathrm{~s}$ with an added $5 \mathrm{~s}$ per cycle. A final extension was carried out at $72{ }^{\circ} \mathrm{C}$ for 5 min.

The five nucleotide mismatches (SNP nt positions 37902, 38036, $38055,38081,38097$ ) were identified by DNA sequence analysis. PCR amplicons underwent enzymic pre-sequencing treatment with $1-2 \mu 1$ PCR product, $1 \mu \mathrm{l}$ each exonuclease I $\left(10 \mathrm{U}^{-1}\right)$ and shrimp

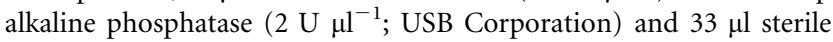
distilled water. The mixture was treated for $15 \mathrm{~min}$ at $37^{\circ} \mathrm{C}$, inactivated for $15 \mathrm{~min}$ at $80{ }^{\circ} \mathrm{C}$ and held at $4{ }^{\circ} \mathrm{C}$ in a thermal cycler. A total volume of $12 \mu \mathrm{l}$ containing $11 \mu \mathrm{l}$ of the clean PCR product and $1 \mu \mathrm{l}$ of either forward or reverse primer $(3.3 \mathrm{pM})$ were sequenced on a 3730 DNA Sequencer (Applied Biosystems) using ABI BigDye Terminator chemistry version 3.1 .

Bioinformatics. The test samples were compared against prototypes in GenBank: strain Dumas (GenBank accession no. X04370), vaccine strains (vOka) Varivax (DQ008355) and Varilrix (DQ008354), CA123 (DQ457052) and VZV subtypes pOka (AB097933), HJO (AJ871403) and M2DR (DQ452050). DNA sequences were checked in the BioEdit version 7.0.4.1 (Hall, 1999) sequencing editing program. Phylogenetic and molecular evolutionary analyses were conducted using MEGA version 4 (Tamura et al., 2007). The non-protein coding sequence of SNPs at positions $685,33725,66288,101464,106262,37902,38036$, 38055,38081 and 38097 of each test sample was compared. The number of differences model was used to assess the support for the major clades and phylogenetic trees constructed using the neighbourjoining method (Saitou \& Nei, 1987) with bootstrap resampling (1000 repeats) (Efron et al., 1996; Felsenstein, 1985). The association of VZV specific genotypes with age, gender and region was measured by a two-way analysis of variance. Results are reported using the new VZV universal nomenclature shown in Table 1.

\section{RESULTS AND DISCUSSION}

A combination of SNP analysis using an HRMA of amplicons from ORF1, $-21,-37,-60$ and -62 and sequence analysis of ORF22 encompassing five SNPs was important for sufficient discrimination between VZV genotypes in this study. The limitation of applying each method alone was that analysis of ORF22 SNPs only does not differentiate European clade 1 from clade 3 strains, instead showing a uniform European genotype (Loparev et al., 2004; Sergeev et al., 2006). Equally, the HRMA of ORF1, $-21,-37,-60$ and -62 did not subdivide clade 2 and clade 4 Japanese strains into their distinctive subtypes. SNP 106262 (ORF62) discriminates only between VZV wild-type strains and the vaccine strain. 
Table 1. Universal VZV nomenclature (Breuer et al., 2010) and strains used in the phylogenetic analysis

\begin{tabular}{|c|c|c|c|c|}
\hline $\begin{array}{l}\text { New universal } \\
\text { nomenclature clade }\end{array}$ & $\begin{array}{l}\text { Reference } \\
\text { strain }\end{array}$ & $\begin{array}{l}\text { Scattered } \\
\text { SNP }^{\star}\end{array}$ & $\begin{array}{c}\text { ORF22 sequence } \\
\text { analysis } \dagger\end{array}$ & $\begin{array}{l}\text { Geographical } \\
\text { distribution }\end{array}$ \\
\hline 1 & Dumas & $\mathrm{C}$ & E1 & Europe \\
\hline 2 & pOka & $\mathrm{J}$ & $\mathrm{J}$ & Far East \\
\hline 3 & $\mathrm{HJO}$ & B & E2 & Europe \\
\hline 4 & M2DR & $\mathrm{J} 2$ & M2 & $\begin{array}{c}\text { Central and South } \\
\text { America, Asia }\end{array}$ \\
\hline 5 & CA123 & A & M1 & Asia, Africa \\
\hline VI $\ddagger$ & & - & M4 & \\
\hline VII & & - & M3 & \\
\hline
\end{tabular}

*Barrett-Muir et al. (2002, 2003).

$\dagger$ Loparev et al. $(2004,2007)$.

\$Clades yet to be confirmed.

\section{Phylogenetics of VZV genotypes}

A phylogram presenting the evolutionary relationship of the VZV genotypes is shown in Fig. 1. Based on the theory that the evolutionary origin of VZV is by co-evolvement with humankind (Grose, 2006), clades representative of different global regions were evident, with some of our isolates matching the profiles of more than one global region.

Comparison of test isolates with the selected prototype reference strains showed that European clade 1 and Japanese clade 2 isolates were $100 \%$ similar to the reference strains Dumas and pOka, respectively. As expected, the vaccine strain (vOka) was most closely related to the Japanese clade 2 cluster, sharing a common ancestor (pOka) from which the live-attenuated VZV vaccine preparation is derived.

Eleven of the test isolates in clade 3 (European) were most similar to HJO, with the exception of four samples (NSW2, NSWra, WA18 and WA21), which shared both clade 1 (SNP 33725) and African/Asian clade 5 (SNP 101464) markers. Only one sample (WA9) grouped in the African/Asian clade 5 had similarity to both clade 3 (SNP 66288) and clade 5. Clade 4 samples $(n=8)$ appeared to be the most genetically varied, with some sharing African, Asian and Japanese markers. For instance, NT6 and NT25 had similar SNPs to clade 2/clade 5 (SNP 101464) and clade 1/clade 2 markers. Genetic variation strongly suggests recombination events with a common ancestry to shared genotypes. Four clinical isolates only were grouped into the novel clade VI, and appear to be genetically closer to European and Asian/ African genotypes in the phylogram. A small number of clade VI strains associated with African immigrants has also been reported in Europe (Loparev et al., 2007).

\section{Prevalence of VZV genotypes}

The prevalence and distribution of VZV genotypes by region are shown in Table 2. The European genotypes (clades 1 and 3 ) predominated, with the majority of isolates distributed in Western Australia $(n=17)$ and the Northern Territory $(n=24)$. Twelve per cent $(9 / 78)$ of the test isolates were African/Asian strains (clade 5) located mainly in Western Australia. Eight of the test isolates were grouped into clade 4, which is common to Central America, South America and Asia, and were for the most part isolated from patients in the Northern Territories (5/ 8 ). Five Japanese strains (clade 2) similar to pOka were found in New South Wales, Western Australia and the Northern Territory.

The prevalence of European clade $1(46 \%)$ and clade 3 (21\%) strains in Australia was lower compared with the USA (80\%) (Loparev et al., 2004), northern and southern Europe $(65 \%)$ (Loparev et al., 2009) and Finland (Koskiniemi et al., 2007). A higher diversity of VZV genotypes in New South Wales was evident when compared with Western Australia and the Northern Territories, with no single genotype presenting an advantage. This may possibly be attributed to a more transient population in New South Wales compared with other states and territories. Two-way analysis of variance showed a significant difference $(P=0.02 ; F=4.01)$ between VZV genotypes alone, with no association between VZV genotype and region. Bonferroni post-tests indicated that clade 1 genotypes significantly predominated in the Northern Territories.

African/Asian strains (clade 5) were second in prevalence to European VZV strains, indicative of an increasing number of these genotypes. Loparev et al. (2007) reported a $7.87 \%$ prevalence of clade 5 genotypes in eastern Australia from specimens collected during 2003 and 2004. This study showed a majority of this circulating strain in Western Australia (6/9) from this more recent collection of isolates. Geographically, clade 5 is widespread in Central Africa and Indochina (Loparev et al., 2000; Quinlivan et al., 2002) and its increasing numbers in Australia are possibly due to the migration of people from 


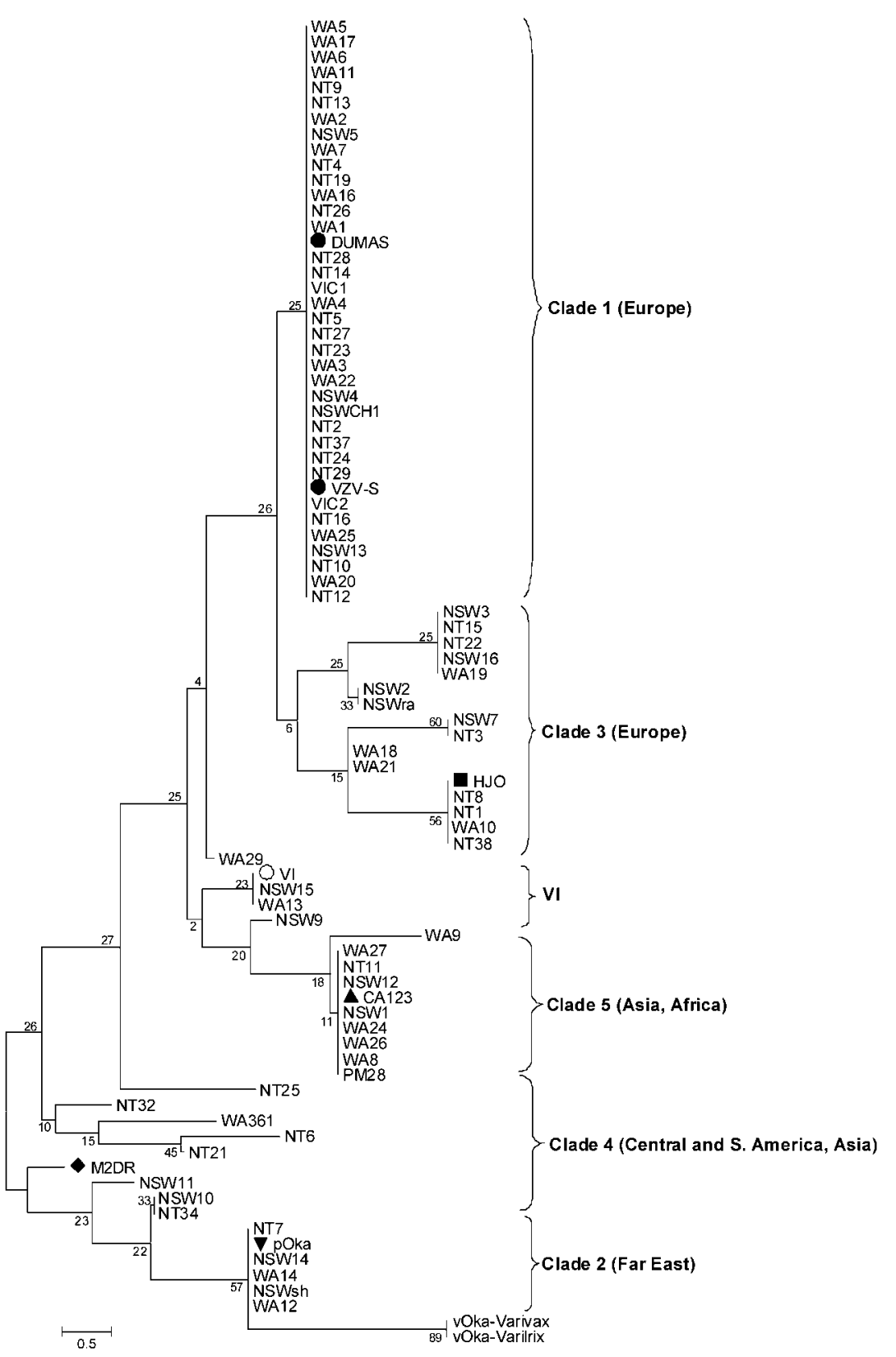

Fig. 1. Phylogenetic tree (neighbour-joining method) of VZV genotypes and GenBank reference strains ( $\bullet$ DUMAS; $\mathbf{\square}, \mathrm{HJO} ; \boldsymbol{\Delta}$, CA123; M2DR; $\boldsymbol{\nabla}$, pOka and vOka) based on single SNP differences in ORF1, -21, -37, -60 and -62 and multi-SNPs in a $484 \mathrm{bp}$ region of ORF22. The percentage of 1000 bootstrap replicates and the regions from which specimens were obtained are indicated. NSW, New South Wales; NT, Northern Territory; WA, Western Australia; VIC, Victoria. Bar, 0.5 substitutions per site. these tropical regions. The distribution and relatedness of strains in Australia demonstrates that the spread of VZV following major human migrations has made a strong contribution to its geographical epidemiology. In future, larger groups should be studied so that inferences can be made on whether the distribution of the different VZV clades is representative of the state and territory.

The age of hospitalized patients ranged from 4 months to 83 years with a median age of 13 years. The range and median age by genotype is shown in Table 2. Interestingly, all of the type VI strains were isolated from children below the age of 7 years. The identification of recombinant strains, especially in young children, suggests previous exposure to a mixture of genotypes. However, no significant relationship was shown between VZV genotype and age of the individual. The epidemiology of VZV infection is different in temperate climates, where most unimmunized children have primary VZV infection in their first decade, compared with tropical regions, where the population may remain susceptible to VZV infection well into adulthood (BarrettMuir et al., 2003; Loparev et al., 2004; Quinlivan et al., 2002).

This study showed a high diversity of VZV genotypes circulating within Australia, with an emergence of recombinant strains. Loparev et al. (2007) previously showed the range of VZV strains in eastern Australia to be broader than in any other region, including Europe, Africa and North America. Moreover, Japanese strains (clade 2) were 
Table 2. Prevalence and distribution of VZV genotypes by age and state/territory

NSW, New South Wales; WA, Western Australia; NT, Northern Territories; VIC, Victoria.

\begin{tabular}{|c|c|c|c|c|c|c|c|}
\hline \multirow[t]{2}{*}{ Clade } & \multicolumn{2}{|c|}{ Age } & \multicolumn{5}{|c|}{$n(\%)$} \\
\hline & Range & Median & NSW & WA & NT & VIC & Total \\
\hline 2 & $1-71$ & 8 & $2(40)$ & $2(40)$ & $1(20)$ & $0(0)$ & $5(6)$ \\
\hline 3 & $0.4-63$ & 5 & $5(31)$ & $4(25)$ & $7(44)$ & $0(0)$ & $16(21)$ \\
\hline 4 & $1-73$ & 17 & $2(25)$ & $1(13)$ & $5(63)$ & $0(0)$ & $8(10)$ \\
\hline Total & & & 17 & 28 & 31 & 2 & $78(100)$ \\
\hline
\end{tabular}

identified, which are absent in Europe (Loparev et al., 2009). The proximity of Australia to the Asia-Pacific regions may in part explain the isolation of Japanese wildtype VZV strains. In this regard, ongoing surveillance of VZV genotypes is important, especially for monitoring future varicella adverse events, as sequences sampled at different times can provide an estimated rate of evolution (Pybus, 2006). The genotypes most associated with hospitalized varicella patients remain unclear, and genotype virulence may be influenced more by the level of host response and immunity than by specific genotype. However, this study does provide preliminary evidence that no individual clades are more likely to be associated with disease requiring hospitalization, although there is a possibility that individual strains will have heightened pathogenicity associated with specific mutations.

\section{ACKNOWLEDGEMENTS}

We thank the following people and institutions for the sourcing of clinical samples: CSL Biotherapies (NSW, Australia) and GlaxoSmithKline (Victoria, Australia) for the vaccine strains, and Alison Abendroth (Centre for Virus Research, Westmead Millennium Institute) for strain Schenke. We also thank Robert Booy, Peter McMinn, Alison Kesson, Leanne Sammuels and David Smith, who generously provided the clinical samples. This work was funded by the New South Wales Department of Health Capacity Building Infrastructure Grant.

\section{REFERENCES}

Barrett-Muir, W., Nichols, R. \& Breuer, J. (2002). Phylogenetic analysis of varicella-zoster virus: evidence of intercontinental spread of genotypes and recombination. J Virol 76, 1971-1979.

Barrett-Muir, W., Scott, F. T., Aaby, P., John, J., Matondo, P., Chaudhry, Q. L., Siqueira, M., Poulsen, A., Yaminishi, K. \& Breuer, J. (2003). Genetic variation of varicella-zoster virus: evidence for geographical separation of strains. J Med Virol 70, S42-S47.

Breuer, J., Grose, C., Norberg, P., Tipples, G. \& Schmid, D. S. (2010). A proposal for a common nomenclature for viral clades that form the species varicella-zoster virus: summary of VZV Nomenclature Meeting 2008, Barts and the London School of Medicine and Dentistry, 24-25 July 2008. J Gen Virol 91, 821-828.
Brisson, M., Edmunds, W. J., Gay, N. J., Law, B. \& De Serres, G. (2000). Modelling the impact of immunization on the epidemiology of varicella zoster virus. Epidemiol Infect 125, 651-669.

Cohen, T. \& Lipsitch, M. (2008). Too little of a good thing: a paradox of moderate infection control. Epidemiology 19, 588-589.

Edmunds, W. J. \& Brisson, M. (2002). The effect of vaccination on the epidemiology of varicella zoster virus. J Infect 44, 211-219.

Efron, B., Halloran, E. \& Holmes, S. (1996). Bootstrap confidence levels for phylogenetic trees. Proc Natl Acad Sci U S A 93, 7085-7090.

Felsenstein, J. (1985). Confidence limits on phylogenies: an approach using the bootstrap. Evolution 39, 783-791.

Grose, C. (2006). Varicella zoster virus: out of Africa and into the research laboratory. Herpes 13, 32-36.

Grose, C., Tyler, S., Peters, G., Hiebert, J., Stephens, G. M., Ruyechan, W. T., Jackson, W., Storlie, J. \& Tipples, G. A. (2004). Complete DNA sequence analyses of the first two varicella-zoster virus glycoprotein E (D150N) mutant viruses found in North America: evolution of genotypes with an accelerated cell spread phenotype. J Virol 78, 6799-6807.

Hall, T. (1999). BioEdit: a user-friendly biological sequence alignment editor and analysis program for Windows 95/98/NT. Nucleic Acids Symp Ser 41, 95-98.

Hope-Simpson, R. E. (1965). The nature of herpes zoster: a long-term study and a new hypothesis. Proc R Soc Med 58, 9-20.

Koskiniemi, M., Lappalainen, M., Schmid, D. S., Rubtcova, E. \& Loparev, V. N. (2007). Genotypic analysis of varicella-zoster virus and its seroprevalence in Finland. Clin Vaccine Immunol 14, 1057-1061.

LaRussa, P., Steinberg, S., Arvin, A., Dwyer, D., Burgess, M., Menegus, M., Rekrut, K., Yamanishi, K. \& Gershon, A. (1998). Polymerase chain reaction and restriction fragment length polymorphism analysis of varicella-zoster virus isolates from the United States and other parts of the world. J Infect Dis 178, S64-S66.

Loparev, V. N., Argaw, T., Krause, P. R., Takayama, M. \& Schmid, D. S. (2000). Improved identification and differentiation of varicella-zoster virus (VZV) wild-type strains and an attenuated varicella vaccine strain using a VZV open reading frame 62-based PCR. J Clin Microbiol 38, 3156-3160.

Loparev, V. N., Gonzalez, A., Deleon-Carnes, M., Tipples, G., Fickenscher, H., Torfason, E. G. \& Schmid, D. S. (2004). Global identification of three major genotypes of varicella-zoster virus: longitudinal clustering and strategies for genotyping. J Virol 78, 83498358.

Loparev, V. N., Rubtcova, E. N., Bostik, V., Govil, D., Birch, C. J., Druce, J. D., Schmid, D. S. \& Croxson, M. C. (2007). Identification of five major and two minor genotypes of varicella-zoster virus strains: a 
practical two-amplicon approach used to genotype clinical isolates in Australia and New Zealand. J Virol 81, 12758-12765.

Loparev, V. N., Rubtcova, E. N., Bostik, V., Tzaneva, V., Sauerbrei, A., Robo, A., Sattler-Dornbacher, E., Hanovcova, I., Stepanova, V. \& other authors (2009). Distribution of varicella-zoster virus (VZV) wild-type genotypes in northern and southern Europe: evidence for high conservation of circulating genotypes. Virology 383, 216-225.

Norberg, P., Liljeqvist, J. A., Bergstrom, T., Sammons, S., Schmid, D. S. \& Loparev, V. N. (2006). Complete-genome phylogenetic approach to varicella-zoster virus evolution: genetic divergence and evidence for recombination. J Virol 80, 9569-9576.

Parker, S. P., Quinlivan, M., Taha, Y. \& Breuer, J. (2006). Genotyping of varicella-zoster virus and the discrimination of Oka vaccine strains by TaqMan real-time PCR. J Clin Microbiol 44, 3911-3914.

Peters, G. A., Tyler, S. D., Grose, C., Severini, A., Gray, M. J., Upton, C. \& Tipples, G. A. (2006). A full-genome phylogenetic analysis of varicella-zoster virus reveals a novel origin of replication-based genotyping scheme and evidence of recombination between major circulating clades. J Virol 80, 9850-9860.

Pybus, O. G. (2006). Model selection and the molecular clock. PLoS Biol 4, e151.

Quinlivan, M., Hawrami, K., Barrett-Muir, W., Aaby, P., Arvin, A., Chow, V. T., John, T. J., Matondo, P., Peiris, M. \& other authors (2002). The molecular epidemiology of varicella-zoster virus: evidence for geographic segregation. J Infect Dis 186, 888-894.
Saitou, N. \& Nei, M. (1987). The neighbor-joining method: a new method for reconstructing phylogenetic trees. Mol Biol Evol 4, 406425.

Sengupta, N., Quinlivan, M. \& Breuer, J. (2009). Comparison of the molecular epidemiology of varicella zoster virus in vaccinated and unvaccinated individuals. In 49th Interscience Conference on Antimicrobial Agents and Chemotherapy (ICAAC). San Francisco, CA, USA. American Society for Microbiology.

Sergeev, N., Rubtcova, E., Chizikov, V., Schmid, D. S. \& Loparev, V. N. (2006). New mosaic subgenotype of varicella-zoster virus in the USA: VZV detection and genotyping by oligonucleotide-microarray. $J$ Virol Methods 136, 8-16.

Taha, Y., Scott, F. T., Parker, S. P., Syndercombe Court, D., Quinlivan, M. L. \& Breuer, J. (2006). Reactivation of 2 genetically distinct varicella-zoster viruses in the same individual. Clin Infect Dis 43, 1301-1303.

Tamura, K., Dudley, J., Nei, M. \& Kumar, S. (2007). MEGA4: Molecular Evolutionary Genetics Analysis (MEGA) software version 4.0. Mol Biol Evol 24, 1596-1599.

Toi, C. S. \& Dwyer, D. E. (2008). Differentiation between vaccine and wild-type varicella-zoster virus genotypes by high-resolution melt analysis of single nucleotide polymorphisms. J Clin Virol 43, 18-24.

Vazquez, M., LaRussa, P. S., Gershon, A. A., Steinberg, S. P., Freudigman, K. \& Shapiro, E. D. (2001). The effectiveness of the varicella vaccine in clinical practice. $N$ Engl J Med 344, 955-960. 